\title{
Monitoring Secchi depth of the Yellow Sea and the East China Sea using a semi-analytical algorithm
}

\author{
Dingfeng Yu ${ }^{\mathrm{a}, \mathrm{b}}$, Bin Zhou ${ }^{\mathrm{a}, \mathrm{b}}$, Qianguo Xing*c ${ }^{\mathrm{c}}$, Yanguo Fan ${ }^{\mathrm{d}}$, Tantan $\mathrm{Li}^{\mathrm{d}}$, Xiaoling Sun ${ }^{\mathrm{a}}$ \\ anstitute of Oceanographic Instrumentation, Shandong Academy of Sciences, Qingdao 266001, \\ Shandong, China \\ ${ }^{\mathrm{b}}$ Shandong Provincial Key lab of Marine Environment Monitoring Technology, Qingdao 266001, \\ Shandong, China \\ ${ }^{c}$ Yantai Institute of Coastal Zone Research, Chinese Academy of Sciences, Yantai 264003, \\ Shandong, China \\ ${ }^{\mathrm{d}}$ China University of Petroleum, Qingdao 266888, Shandong, China
}

\begin{abstract}
Secchi depth, an important optical characteristic of water, is a useful index of water quality and is widely used in many environmental studies. The Yellow Sea and the East China Sea are typical case 2 waters, where concentrations of suspended matter, phytoplankton pigments, and colored dissolved organic matter are higher than those in other open oceans. Two cruises were conducted to investigate the water optical characteristics in the Yellow Sea and the East China Sea in May and June, 2009. 62 water sampling stations of Secchi disk depth were measured in situ in day time, and their values were in the range of 0.0112 to $15.6 \mathrm{~m}$ with the mean of $6.72 \mathrm{~m}$ and a standard deviation of $3.18 \mathrm{~m}$. In this paper, we adapted a quasi-analytical algorithm to estimate the Secchi depth from satellite ocean data in both coastal and oceanic waters. The development of the algorithm is based on the use of in situ measurements and 8-day MODIS-Aqua remote sensing reflectance data with $4 \mathrm{~km}$ spatial resolution. More than 39 matchups were compiled for the MODIS sensor by spatial-temporal matching. The comparison between water transparency retrievals from remote sensing data and in situ measurements yields showed that the determination coefficient was 0.60 and a root mean square error of $8.4 \mathrm{~m}$. This study suggests that the quasi-analytical algorithm provide a promising result on in situ data. In the future, maps of ocean transparency for this area will be derived using this algorithm.
\end{abstract}

Keywords: Secchi disk depth, MODIS, Retrieval, the Yellow Sea, the East China Sea

\section{INTRODUCTION}

Secchi disk depth (SDD), as the earliest oceanographic measurement of water transparency ${ }^{[1]}$, is a useful index of water quality and is widely used in many environmental studies, which originated from the nineteenth century and has already become a widely used tool for measuring water clarity. However, traditional measurements of water transparency are often affected by the sea conditions. Although the in situ sampling methods provide accurate measurements, they are time-consuming, and they can not give the spatial overview that is necessary for monitoring and measuring water clarity.

Satellite remote sensing is recognised as a valuable tool for monitoring water quality in large areas, especially for remote and inaccessible regions. Satellite remote sensing technique has been found to be an important tool for monitoring Secchi disk depth ${ }^{[2]}$. The algorithms for estimating water transparency using remotely-sensed data can be summarized as three types: firstly, the empirical algorithm estiblished by relationship between water transparency and water optical properties. Obviously, this kind of model is simple and easy to achieve. However, the relationships are more specific and cannot be applied different regions. Secondly, the physical algorithm based on the radiative transfer theory via simulating the spectra at the top of atmosphere with Secchi disk depths and atmosphere conditions. Using the radiance at the top of

*qgxing@yic.ac.cn

Ocean Remote Sensing and Monitoring from Space, edited by Robert J. Frouin, Delu Pan,

Hiroshi Murakami, Young Baek Son, Proc. of SPIE Vol. 9261, 92611 · C 2014 SPIE

CCC code: $0277-786 \mathrm{X} / 14 / \$ 18 \cdot$ doi: $10.1117 / 12.2068166$

Proc. of SPIE Vol. $926192611 \mathrm{~J}-1$ 
atmosphere measured by some instrument but not reflectance, the water clarity can be estimated by menthods optimization and principal component analysis and neural network. Thirdly, the semi-analytical algorithm based on relationship between water transparency and inherent optical properties of water. The algorithm combines physics with some statistical methods and is a promising technique for retrieving water concents ${ }^{[3,4]}$. Thus, a semi-analytical algorithm will be employed to estimate water clarity in this study.

The Yellow Sea and the East China Sea are typical case 2 waters, where concentrations of suspended matter, phytoplankton pigments, and coloured dissolved organic matter are higher than those in other open oceans, e.g., the Pacific. Large scale of green tide has occurred in this region every year since 2007 and has become one of important local ecological phenomena, which has brought great economic losses and influences marine ecosystems. Changes in water transparency have been widely linked to eutrophication and water quality ${ }^{[5]}$. Thus, for monitoring the status of ecological environments in the East China Seas, it is necessary to find a model that can be used to estimate Secchi disk depth and estimate it in this area. The objective of this study is to establish a semi-analytical algorithm using MODISAqua remote sensing reflectance and field data for retrieving Secchi disk depth in the Yellow Sea and the East China Sea.

\section{DATA AND METHODS}

\subsection{Field data}

Two cruises were carried out in the Yellow Sea and the East China Sea between May and June in 2009. The main survey areas of the first one, which was conducted on the ocean research vessel "Science no.1" from 15th to 31st May in 2009, were the South Yellow Sea and the East China Sea. The second one was conducted on the research ship "Science no.3" from 15th to 20th June in 2009, and the North Yellow Sea was main area of the investigation. In addition, 62 water sampling stations of water clarity were collected in this region (Figure 1).

Secchi disk transparency measurements were made with a standard Secchi disk (diameter 30 centimeters) with alternate black and white quadrants. The disk was lowered into the water body on the side of the ship as far as it is just visible, and their values were in the range of 0.0112 to $15.6 \mathrm{~m}$ with the mean of $6.72 \mathrm{~m}$ and a standard deviation of $3.18 \mathrm{~m}$. 


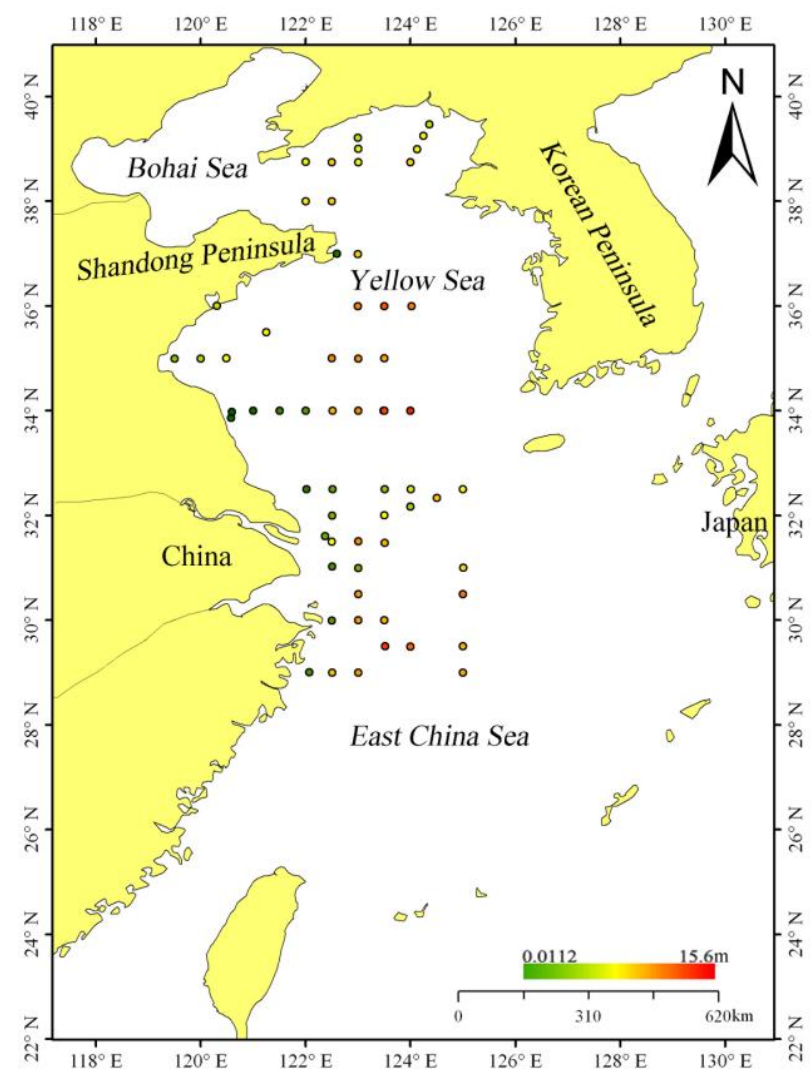

Figure 1. Map Showing the Sampling Sites in the East China Seas

\subsection{Satellite data}

The Moderate Resolution Imaging Spectroradiometer (MODIS) instruments were onboard the U.S. National Aeronaautics and Space Administration (NASA) satellites, Terra and Aqua, launched in 1999 and 2002, respectively. The remote-sensing reflectance data, including channel bands centered at 412, 443, 469, 488, 531, 547, 555, 645, 667, and $678 \mathrm{~nm}$ respectively, were Level 3 Standard Mapped Image (SMI) products observed by MODIS-Aqua. And all the data had the 8-day temporal resolution and $4 \times 4 \mathrm{~km}$ spatial resolution. The MODIS data were provided by NASA Goddard Space Flight Center Ocean Bilogy Processing Group (http://oceandata.sci.gsfc.nasa.gov/MODISA/L3SMI/).

\subsection{Data processing}

We matched 8-day remote sensing reflectance data (Julian days 137-144, 145-152, and 169-176 in 2009) with in situ Secchi disk depth by temporal-spatial matching. First, backscattering coefficients and absorption coefficients were reterived using the remote sensing reflectance data. Then, a quasi-analytical algorithm for monitoring Secchi depth from eatimated scattering and absorption coefficients is presented.

\subsection{Accuracy assessment}

In order to evaluate algorithm performance, the RMSE (root mean square error) and RE (relative error) are used in this study. These two statistics are described by the following equations:

$$
\begin{aligned}
R M S E & =\sqrt{\frac{\sum_{i=1}^{n}\left(x_{\text {est }, i}-x_{\text {mea }, i}\right)^{2}}{n}} \\
R E & =\frac{\left|x_{\text {est }}-x_{\text {mea }}\right|}{x_{\text {mea }}} \times 100 \%
\end{aligned}
$$

where, $x_{\text {est }}$ is the estimated transparency, $x_{\text {mea }}$ is the measured transparency, and $n$ is the number of elements. 


\section{DISCUSSION}

\subsection{The quasi-analytical algorithm}

With the development of the transparency of remote sensing inversion algorithm study, the researchers measured the transparency of the optical properties of water combined with the optical radiation transfer theory underwater establish a semi-transparent analysis of remote sensing inversion mode. Doron et al ${ }^{[6]}$ proposed a theory of retrieving transparency on the base of attenuation and diffuse coefficients at $490 \mathrm{~nm}$, which based on the theory of Tyler ${ }^{[7]}$ and Preisendorfer ${ }^{[8]}$.The algorithm was applied to estimate Sechi depth in the Tonkin Bay and the nearshore waters of the western Taiwan Strait in China.

When light propagates in a homogeneous medium, the transparency in the vertical direction can be expressed as:

$$
S D D=\frac{\ln \left(\frac{C_{0}}{C_{\min }}\right)}{K_{d}(v)+c(v)}
$$

where SDD is Secchi disk depth, $C_{\min }$ is the inherent contrast between the disk and background water, $C_{\min }$ is the minimum apparent contrast properties by the eye, $K_{d}(v)$ is the visual photopic vertical diffuse attenuation coefficient of the water, and $c(v)$ is the photopic beam attenuation coefficient. According to Preisendorfer ${ }^{[9]}, \ln \left(\frac{C_{0}}{C_{\min }}\right)$ can vary, with the submerged disk reflectance, the reflectance of the background and $C_{\min }$, between 5 and 10 .

According to Doron et al. ${ }^{[6]}, K_{d}(v)+c(v)$ is strongly related to $K_{d}(490)+c(490)$ with a polynomial function, which can be expressed using the following equation:

$$
K_{d}(v)+c(v)=0.0989 x^{2}+0.8879 x-0.0467
$$

where $x$ is $K_{d}(490)+c(490)$, and $K_{d}(490)$ can be estimated from absorption and backscattering coefficients at the wavelength of $490 \mathrm{~nm}^{[10]}$.

$$
K_{d}(490)=a(490)+3.47 \times b_{b}(490)
$$

$c(490)$ is the function of absorption, scattering and backscattering coefficients for the water at the wavelength of 490 $\mathrm{nm}^{[11,12]}$, as the following expression:

$$
c(490)=a(490)+b_{b p}(490) / 0.02+b_{w}(490)
$$

where $a(490), b_{b}(490)$ and $b_{b p}(490)$ can be estimated from the quasi-analytical algorithm, and $b_{w}(490)$ is $0.0031 \mathrm{~m}^{-1[13]}$ In the latest quasi-analytical algorithm, three bands were recommended as the reference wavelength ${ }^{[14]}$. In this paper, 550 $\mathrm{nm}$ is selected as the reference wavelength, and the steps of QAA to drive absorption and backscattering coefficients from remote sensing reflectance with $555 \mathrm{~nm}$ as the table 1 .

Table 1. Steps of the QAA to drive absorption and backscattering coefficients from remote-sensing reflectance with $555 \mathrm{~nm}$ as the reference wavelength

\begin{tabular}{|l|l|l|c|}
\hline step & \multicolumn{1}{|c|}{ property } & \multicolumn{1}{c|}{ Math formula } & approach \\
\hline 1 & $r_{r s}$ & $=R_{r s} /\left(0.52+1.7 R_{r s}\right)$ & semianalytical \\
\hline
\end{tabular}




\begin{tabular}{|l|l|l|l|}
\hline 2 & $u(\lambda)=\frac{b_{b}(\lambda)}{a(\lambda)+b_{b}(\lambda)}$ & $=\frac{-g_{0}+\left[g_{0}{ }^{2}+4 g_{1} r_{r s}\right]^{1 / 2}}{2 g_{1}}$ & semianalytical \\
\hline 3 & $a(555)$ & $=g_{0}=0.089, g_{1}=0.125$ & \\
& $\chi=\log \left(\frac{r_{r s}(443)+r_{r s}(490)+10^{-1.146-1.366 x-0.469 \chi^{2}}}{r_{r s}(555)+5 \frac{r_{r s}(667)}{r_{r s}(490)} r_{r s}(667)}\right)$ & empirical \\
\hline 4 & $b_{b p}(555)$ & $=\frac{u(555) a(555)}{1-u(555)}-b_{b w}(555)$ & \\
\hline 5 & $\eta$ & $=2.0\left\lfloor 1-1.2 \exp \left(-0.9 \frac{r_{r s}(443)}{r_{r s}(555)}\right)\right\rfloor$ & analytical \\
\hline 6 & $b_{b p}(\lambda)$ & $=b_{b p}(555)\left(\frac{555}{\lambda}\right)^{\eta}$ & empirical \\
\hline 7 & $a(\lambda)$ & $=\frac{[1-u(\lambda)]\left\lfloor b_{b w}(\lambda)+b_{b p}(\lambda)\right\rfloor}{u(\lambda)}$ & analytical \\
\hline$a_{w}(555)=0.0596{ }^{[15]}$. & & \\
\hline
\end{tabular}

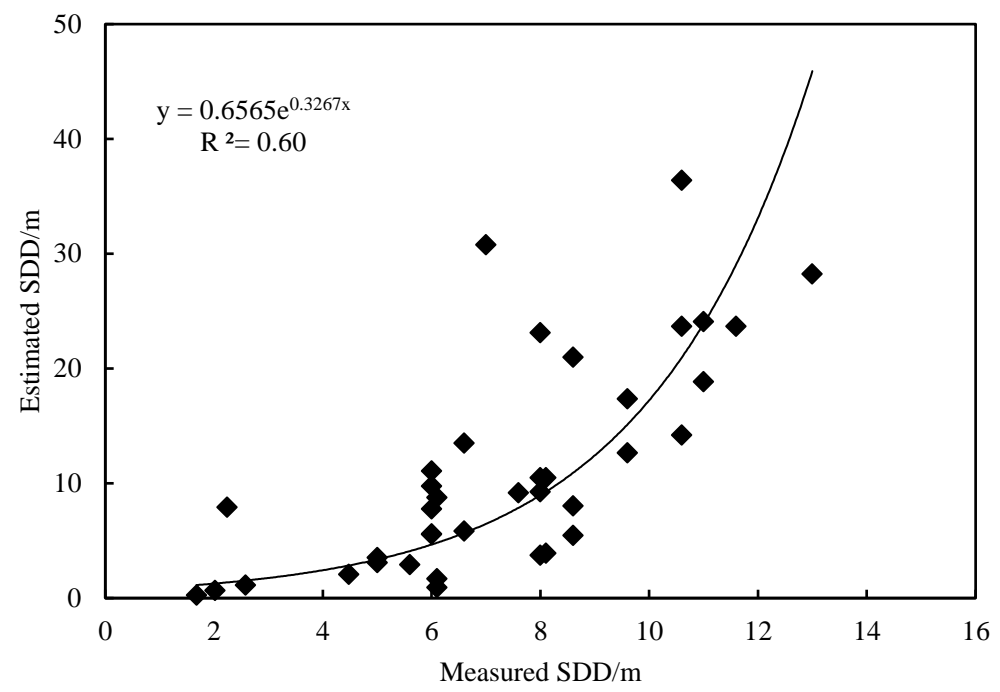

Figure 2. Comparison between Measured and Retrieved SDD Using the Semi-analytical Algorithm

As shown in figure 2, in the East China region, the retrieved Secchi disk depth using the semi-analytical algorithm are not consistent with the measured transparency, with the relative error of $78.4 \%$, the maximum relative error is $243.3 \%$, the smallest relative error is $7.04 \%$, the root mean square error of $8.48 \mathrm{~m}$. 


\subsection{Uncertainty analysis}

\subsubsection{Measured Secchi disk depth}

Collecting water transparency in the field is influenced by many factors. Different observers, their vision, proficiency and even physical condition will affect the transparency of the readings. In addition, different elevation angles and the light intensity will also affect the measured transparency. Transparency of the disk itself, including its size and the white area on the disk, will affect the measured Secchi depth. For empirical and semi-analytical algorithms, the measurement error of water transparency is bound to affect the accuracy of the models.

\subsubsection{Temporal matching method}

Due to cloud cover, while the measured data is limited, few can match the amount of data. Therefore, the time window is expanded to $8 \mathrm{~d}$ or a month in this paper. In addition, the remote sensing data have a $4 \times 4 \mathrm{~km}$ spatial resolution, while each station of measuring water transparency is only one point. Obviously, there is an error, but it is a common phenomenon in remote sensing.

\section{CONCLUSION}

Two cruises were carried out between May and June in 2009 in the Yellow Sea and the East China Sea. In situ measurements of Secchi disk depth matched with the 8-day MODIS-Aqua remote sensing reflectance data were used for further analysis. we adapted a quasi-analytical algorithm to estimate the Secchi depth from satellite ocean data in both coastal and oceanic waters. The development of the algorithm is based on the use of in situ measurements and 8-day MODIS-Aqua remote sensing reflectance data with $4 \mathrm{~km}$ spatial resolution. More than 39 matchups were compiled for the MODIS sensor by spatial-temporal matching. The comparison between water transparency retrievals from remote sensing data and in situ measurements yields showed that the determination coefficient was 0.60 and a root mean square error of $8.4 \mathrm{~m}$. This study suggests that the quasi-analytical algorithm provide a promising result on in situ data. In the future, maps of ocean transparency for this area will be derived using this algorithm.

\section{ACKNOWLEDGEMENTS}

This work was supported by Strategic Priority Research Programme of Chinese Academy of Sciences under contract No. XDA11020403, a Science and Technology Planning Project Funded by the Shandong province, China under contract No. J08LD55, and Technology Foundation for Selected Overseas Chinese Scholar by Ministry of Personnel of China under contract No. SR-12-10-1. The authors thank all the crews for assistance in sampling onboard.

\section{REFERENCES}

[1] Falkowski, P. G. and Cara W., "Phytoplankton productivity in the North Pacific Ocean since 1900 and implications for absorption of anthropogenic $\mathrm{CO}_{2}$," Nature, 358(6389), 741-743 (1992).

[2] Mantas, V. M., Pereira, A. J. S. C., Neto, J., Patrício, J. and Marques, J. C., "Monitoring estuarine water quality using satellite imagery. The Mondego river estuary (Portugal) as a case study," Ocean \& Coastal Management, 72, 1-9 (2011).

[3] Carder, K. L., Chen, F. R., Lee, Z. P., Hawes, S. K. and Kamykowski, D, "Semianalytic Moderate Resolution Imaging Spectrometer algorithms for chlorophyll-a and absorption with bio-optical domains based on nitratedepletion temperatures," Journal of Geophysical Research, 104(C3), 5403-5421 (1999).

[4] Xu, J. P., Zhang B., Song, K. S., Wang, Z. M. and Duan, H. T., "Estimation of chlorophyll-a concentration in Lake Xinmiao based on a semi-analytical model," Journal of Infrared and Millimeter Waves, 27(3), 197-201 (2008).

[5] Fleming-Lehtinen, V. and Laamanen, M., "Long-term changes in Secchi depth and the role of phytoplankton in explaining light attenuation in the Baltic Sea," Estuarine, Coastal and Shelf Science, 102, 1-10 (2012).

[6] Doron, M., Babin, M., Mangin, A. and Hembise, O., "Estimation of light penetration, and horizontal and vertical visibility in oceanic and coastal waters from surface reflectance," Journal of Geophysical Research, 112(C6), C06003(2007)

[7] Tyler, J. E., "The Secchi disc," Limnology and Oceanography, 1-6 (1968).

[8] Collins, M. and Banner, F., "Secchi disc depths, suspensions and circulation, northeastern Mediterranean Sea," Marine Geology, 31(1-2): M39-M46 (1979)

[9] Preisendorfer, R. W., "Secchi disk science: Visual optics of natural waters," Limnology and Oceanography, 31(5), 909-926 (1986). 
[10] Wei, G. M., Shang, S. L., Lee, Z. P. and Lan, J., "An IOP-based remote-sensing algorithm for Secchi depth and its validation for the Gulf of Tonkin.," High Technology Letter, 19(9), 977-982 (2009).

[11] Lee, Z. P., Du, K. P. and Arnone, R., "A model for the diffuse attenuation coefficient of downwelling irradiance," Journal of Geophysical Research, 110(C2): C02016 (2005).

[12] Gordon, H. R., Can the Lambert-Beer law be applied to the diffuse attenuation coefficient of ocean water? [J]. Limnology and Oceanography, 34(8), 1389-1409 (1989).

[13] Smith, R. C., Baker, K. S., "Optical properties of the clearest natural waters (200-800 nm)," Applied optics, 20(2): 177-84 (1981).

[14] Lee, Z. P., Lubac, B., Werdell, J. and Arnone, R., "An Update of the Quasi-Analytical Algorithm (QAA_V5)," International Ocean Color Group Software Report, (2009).

[15] Pope, R. M. and Fry, E. S., "Absorption spectrum (380-700 nm) of pure water. II. Integrating cavity measurements," Applied optics, 36(33), 8710-8723 (1997). 